\title{
Recurrent Colon Adenocarcinoma
}

National Cancer Institute

\section{Source}

National Cancer Institute. Recurrent Colon Adenocarcinoma. NCI Thesaurus. Code C162442.

The reemergence of colon adenocarcinoma after a period of remission. 